\title{
How wealthy are orphans and vulnerable children households in a metropolitan community, South-West Nigeria?
}

\author{
Oyindamola B. Yusuf ${ }^{1}$, Temitayo Odusote ${ }^{2}$, Olusanmi lyabode ${ }^{3}$, Joanna Nwosu ${ }^{2}$, \\ Tessie Phillips-Ononye ${ }^{2}$, Ayo S. Adebowale ${ }^{1}$ and Elijah A. Bamgboye ${ }^{3}$ \\ ${ }^{1}$ Department of Epidemiology and Medical Statistics, \\ University of Ibadan, Nigeria. \\ ${ }^{2}$ United States Agency for International Development (USAID),
}

\author{
Abuja, Nigeria \\ ${ }^{3}$ Association for Reproductive and Family Health, \\ Ibadan, Nigeria \\ bidemiyusuf1@gmail.com
}

\begin{abstract}
Context/Background: Responding to the needs of orphans and vulnerable children (OVC) remains a public health challenge. In Nigeria, disparities in wealth among OVC has not been previously documented. Therefore, this study determined the socio-economic status of Orphans and Vulnerable Children (OVC) in relation to service areas in Lagos Nigeria.

Data Sources and Methods: A cross-sectional survey was conducted in five local government areas. A child vulnerability assessment form was used to identify 6656 OVC households. A pretested semistructured questionnaire was used to collect information on socio-demographic characteristics, and items relating to service areas: economy, education, food security, shelter, health and psychosocial issues. Socio-economic status was measured by wealth index; developed using principal component analysis.

Results: Child access to healthcare services was lower (46.2\%) among poorer females compared to males $(50.0 \%)$. Access to legal protection was low in all socio-economic categories for both males and females. Food insecurity was significantly higher in the lower wealth quintiles. The odds of adequate shelter increased with increasing wealth quintiles.

Conclusion: There were considerable socio-economic inequalities in the access of orphans and vulnerable children to the service areas.
\end{abstract}

Keywords: Wealth Index, Orphans and Vulnerable Children, SouthWest Nigeria.

\section{Introduction}

In Nigeria, about 17.5 million children are categorized as vulnerable. (FMWSD, 2007). Responding to the needs of these vulnerable children remains a public health challenge. In the country, prior to 2008, there were standard guidelines and practices based on a national plan of action, which focused on the provision of direct services to individual children rather than families or communities. However, the national priority agenda encouraged family-centered intervention at the household level rather than giving the children themselves. By 2008, the guidelines were revised and became family centered, which was an improvement over the old one.

These guidelines covers the seven core service areas which are essential components targeting orphans and vulnerable children (OVC). These areas include: Health, Nutrition and food security, psychosocial support, protection, education and training, shelter and care and Household economic strengthening (HES). Vulnerable children may require services in only some of these areas depending on the child's circumstances. Household economic strengthening services enhance the economic capacity of vulnerable households to be self reliant and provide for the basic needs of their children. (FMWSD 20I4).

The government as well as several nongovernmental organizations have responded to the problems faced by OVC in different states of the country including Lagos. Of the 6349 children interviewed in a national survey, 1059 (16.7\%) were OVC (NDHS report, 2013). The Lagos situation is similar to other states where the problems of OVC 
exists in all areas such as education, health, food security, HES as well as psychosocial support (Christain Aid 2007).

The definition of Orphans and Vulnerable Children (OVC) varies across countries. The UN Convention on the Rights of the Child defines a child as "every human being below the age of 18 years. An Orphan is a child aged below 18 years whose mother, father, or both have died. However, there are other children who are referred to as social orphans even though one or both parents may still be alive but have been unable to perform parental duties because of illness or acute poverty among other reasons. A child is said to be an orphan and vulnerable if he/she is under the age of 18 years and currently at high risk of lacking adequate care and protection. Such a child would have one or more of the following characteristics: orphaned by the death of one or both parents; abandoned by parents; living in extreme poverty; living with a disability; affected by armed conflicts; abused by parents or their carers; malnourished due to extreme poverty; HIVpositive; and finally, those marginalized, stigmatized, or even discriminated against.

Nigeria has been categorized as a developing country and access to social infrastructures like education, stable electricity supply, good roads, portable water, good hygiene and good health services is limited. In this context, the poor particularly the underprivileged are mostly at the receiving end. These problems therefore become compounded and more critical when a child is an orphan and living in a poor household. Thus, their health and socio-economic advancement in life may be compromised. Consequently, their chances of survival become shortened when compared to their counterparts living in rich or better households. Emerging diseases and poor socioeconomic conditions in Nigeria has compounded the problems faced by OVC in Nigeria. (Nigeria Research Situation Analysis, 2009; Egharevba, 2017).

\section{Literature review and theoretical framework}

A national survey carried out across the six geopolitical zones in Nigeria shows that $6.0 \%$ of children less than 18 years have one or both parents deceased. Previous reports showed that $9 \%$ of children are orphans or are vulnerable due to illnesses among adult household members. Orphans and vulnerable children are less likely to be attending school than non-OVC. About $34.0 \%$ of OVC and $9.0 \%$ of non-OVC were underweight and female OVC were more likely than male OVC to engage in sexual activity before age 15. Also $95.0 \%$ of OVC have not received any type of medical, emotional, social, or material assistance or any school-related assistance (NDHS, 20I3). However, between Jan $I^{\text {st }}$ 2013 and June 2015, The Association for Family and Reproductive Health (ARFH) has provided 15554 orphans and vulnerable children with education, health, nutritional and Psychosocial support across 12 States (including Lagos) in Nigeria through The Global Fund to Fight AIDS, Tuberculosis and Malaria (GFATM) Round 9 Phase II HIV/AIDS Grant. The ARFH projects have specifically targeted children infected with or made vulnerable through HIV/AIDS. The Community Health Information Education Forum (CHIEF) a community-based, health development oriented, non-governmental organization (NGO), also has programs for OVC in lagos state as part of their activities in preventing diseases, promoting the health, rights and socioeconomic development status of disadvantaged women, children and youths in community settings.

Despite the decline in HIV adult prevalence and increased access to treatment, the number of children affected by or vulnerable to HIV remains high. Reports also showed that of the 16.6 million children (aged 0-17) infected, who have lost one or both parents to AIDS, I4.8 million are in sub-Saharan Africa (UN, 20II). So far, an estimated 17 million children lost one or both parents due to AIDS over the 30 year period of the epidemic and $90 \%$ of these children live in sub-Saharan Africa (WHO, 20II). Despite the various responses/programs to combat HIV, the burden has continued to increase in Nigeria, particularly in terms of the number of people infected and affected one of which is the Orphans and Vulnerable Children (OVC). Until recently, the response in Nigeria to the crisis of OVC brought about by HIV/AIDS and other causes including road accidents, maternal mortality, ethnic and sectarian crises, poverty, and gender inequality was largely driven by the poor living conditions and nutritional status of OVC. The extended family structure which is known as the major care and support providers for affected children is fading away. Moreover, the needs of OVC often overwhelm the capacity of the structure and community to care for them, and the national response has not matched the enormity of the problem. In recent times, the Federal Republic of Nigeria has strengthened its commitment on the concern of OVC. As part of the country's response to the OVC crisis, a national priority agenda was developed to assure and improve the quality of services provided for the well-being, protection, and development of the children considered most vulnerable in Nigeria. The Federal Ministry of Women Affairs and Social Development has also helped in the OVC situation. The guidelines developed by the federal ministry also aim to strengthen existing safety nets and provide additional 
resources without undermining the capacity of communities and families to care for and protect vulnerable children (Federal Ministry of Women Affairs and Social Development, 2007).

Disparities or inequalities in wealth have been documented by several studies (Dalstra et al 2005, Rutsein 2008, Vukovic and Bjegovic 2008). However, for the OVC, none has been reported in Nigeria. Household economic strengthening which is one of the seven OVC core service areas is important in this regard. Previous studies have shown that household wealth is positively and significantly associated with health care access (Oritz, 2007; Celik, 2000). For the OVC, this is not known. Poverty and food insecurity are likely to increase sexual risk among orphans and vulnerable children. Reducing poverty by supporting caregivers of OVC requires data that is disaggregated by age, gender and socio economic status (a proxy for HES). Previous studies have documented that caregivers of OVC are overburdened and not economically capable of providing for them (Thielman, 2012). However, the magnitude of these problems in terms of the socio economic status as well as the OVC service areas in Nigeria is not known. Studies in Rwanda showed that OVC households tended to be poorer than non OVC households and majority of OVC households heads had no education. Half of all households were classified as "very poor" 12\% lived in abject poverty and the rest were classified as poor (UNICEF, 2008). Only $13.6 \%$ of all OVC households had incomes/own production valued at over US\$0.33 per day or US\$I0 per month. Measuring the poverty status of OVC or socio economic status of OVC is important particularly in Lagos-State where some of its inhabitants live in the slums. In this study, we hypothesize that access to key service areas may vary by social economic status. This will underline the importance to focus support on households most in need and suggest prioritizations for external support. Against the backdrop of limited information on OVC living conditions and their access to the service areas, we developed the wealth index for OVC in LagosState and also investigated the association between wealth index and the key OVC service areas.

\section{Data and methods Study Setting}

Lagos state is the smallest state in Nigeria in land mass yet it is densely populated. As at 2006, the population of Lagos State was 17.5 million, (based on the parallel count conducted by the state during the National Census) with a growth rate of $3.2 \%$, the state today has a population of over 2I Million. The UN estimates that at its present growth rate, Lagos state will be third largest mega city in the world in 3801 years to come. The state is located on the southwestern part of Nigeria and bounded in the North and East by Ogun State of Nigeria, in the West by the Republic of Benin, and in the South by the Atlantic Ocean. There are 20 local government areas in the state.

\section{Study design and Population}

A descriptive, cross sectional survey was conducted in OVC (aged 0-17years) households in 5 purposefully selected Local Government Areas (LGAs) in Lagos-State. The LGAs are; Agege, Ajeromi/lfelodun, Badagry, Ojo and Kosofe. In these LGAs, OVC household clusters were designed and 6656 OVC households were identified using a vulnerability index tool. Thereafter, 1250 OVC households were systematically selected from the list of the identified OVC households. The survey was conducted using interviewer administered questionnaire on OVC and their caregivers. Care givers were made to respond to questions on the general household conditions and issues on OVC aged 0-9 years while OVC aged 10-17years responded to the questions relevant to them independently.

Households living conditions were used to measure socioeconomic status. This method of measuring the asset index has been in existence since 1999 (Filmer and Pritchett, 1999). The method uses household assets such as goods to describe household welfare instead of using income. A previous study had concluded that the wealth index better represents long term (permanent) economic status and is also much easier to determine (Rustein and Johnson, 2004).

\section{Selection of Households}

A purposive sample was used to identify the caregivers of OVC. The households were identified based on the listing done by the community volunteers trained by a consultant medical demographer. A household vulnerability assessment form was used to identify households with OVC based on an index of vulnerability which was determined using scores categorized as follows: Most vulnerable: 2I-28 points, More vulnerable: I4- 20 points and Vulnerable: 7-I3 points. Most vulnerable and more vulnerable households were selected for interview.

\section{Data Collection}

Data were collected using semi-structured, interviewer-administered questionnaires. Information was collected on socio demographic characteristics as well as the items relating to the key OVC service areas: economy, education/work, food security, 
shelter, health and protection, psychosocial, care and support. The questionnaire was in separate sections: caregiver items /questions, questions for the 0-9yrs OVC and 10-I7yrs OVC. Background characteristics of caregiver (sex, age, level of education, duration of stay in residence, literacy level, working status, marital status and religion) were collected. In addition, questions were asked on housing conditions and assets (main material for dwelling floor, main material for walls, main materials for roof, number of bedrooms, fuel used for cooking, main source of drinking water, type of toilet facility, location of toilet facility, source of power supply, possession of house amenities, possession of mobile phones). Socio economic status was measured by wealth index which was developed using principal component analysis.

\section{Data analysis}

Relevant tables and graphs were generated. Descriptive statistics such as means, medians, standard deviation and ranges were used to summarize quantitative variables while categorical variables were summarized with percentages. The Chi square test was used to investigate associations between wealth index and the key service areas including other variables relating to them. Binary logistic regression models were fitted to further investigate the strength of the associations between wealth index and the key service areas. Several models were developed for the different outcome variables. The outcome variable in each of the binary logistic regression analysis was the core service areas such as access to health, access to legal protection, safety from abuse, etc. These outcome variables were measured in terms of yes/no, hence binary logistic regression models were fitted. All analysis was done using Stata (Stata Corp., 2007) at 5\% level of significance.

\section{Construction of wealth index}

The asset approach was used to create the wealth index. All household possessions were used in a principal component analysis.

The principal components are linear functions of the original variables of the form

$$
Y_{j}=e_{1 j} X_{1}+e_{2 j} X_{2}+\ldots . .+e_{n j} X_{n}
$$

with

$$
\begin{aligned}
& \left(e_{1 j}\right)^{2}+\left(e_{2 j}\right)^{2}+\ldots \ldots \ldots+\left(e_{n j}\right)^{2} \\
& \text { for } j=1,2, \ldots \ldots \ldots ., n
\end{aligned}
$$

$X_{1}, X_{2}, \ldots, X_{n}$ are the optimally-weighted observed variables

$e_{i j}$ are the regression coefficients (or weights) for observed variable $\mathrm{n}$, used in creating the principal components.

The PCA method has the advantage of avoiding the negative influence of high inter-correlation among variables (Mohanty 2008). Indicator variables were standardized (i.e. normalized) and factor loadings were then calculated. For each household, indicator values were multiplied by the loadings and summed to produce the household index value. The first of the factors produced was used to represent the wealth index. The households or individuals were ordered and distribution was divided into quintiles. PCA was used to extract the first principal component of assets variables. The extraction revealed there were 21 components with Eigen values greater than 1.0 and explained $64.8 \%$ of variations in the data.

\section{Results \\ Characteristics of OVC and caregivers}

There were I 300 caregivers with a mean age of 43.1 \pm 13.9yrs and a sex ratio of I:3.6. There were 1066 children aged $0-9$ years of which $49.2 \%$ were females and 757 children aged 10-17years of which $51.8 \%$ were females. Household density (Mean number of people in household) was estimated to be 5.I.

The results showed that $23.3 \%$ and $18.7 \%$ of the male and female caregivers respectively were from the richest households while $22.4 \%$ and $18.8 \%$ were from the poorest. The proportion of caregivers in the richest households increases with increasing level of education. For instance, $8.7 \%$ of caregivers who never had any formal education were in the richest households compared to $39.6 \%$ of those with tertiary education. Households where the caregivers were not married had the least proportion of poorest caregivers while highest proportion of the poorest was found among the divorced/separated caregivers. Table I shows the socio demographic characteristics of the caregivers by the wealth quintiles. Furthermore, $19.5 \%$ of male OVC were from poorest households compared with $20.9 \%$ of the females, while $21.6 \%$ male OVC where from richest households compared to $17.9 \%$ of the females. Figure I shows the proportion of OVC in each wealth quintile by gender. 
Table I: Socio demographic characteristics of the caregivers by the wealth quintiles

\begin{tabular}{llllll}
\hline & Poorest & poor & Middle & Richer & Richest \\
\hline Sex & & & & & \\
Male & 22.4 & 18.6 & 18.6 & 17.2 & 23.3 \\
Female & 18.8 & 21.0 & 20.3 & 21.3 & 18.7 \\
& & & & & \\
Education & 27.9 & 25.7 & 20.8 & 17.0 & 8.7 \\
None & 21.3 & 18.9 & 22.4 & 20.6 & 16.7 \\
Primary & 14.4 & 18.7 & 17.9 & 22.2 & 26.7 \\
Secondary & 10.4 & 14.6 & 18.8 & 16.7 & 39.6 \\
Tertiary & & & & & \\
Marital Status & 17.3 & 19.8 & 18.5 & 20.4 & 24.0 \\
Married & 13.5 & 21.3 & 17.7 & 19.1 & 28.4 \\
Not married & 30.5 & 23.2 & 21.1 & 14.7 & 10.5 \\
Divorced/separated & 23.8 & 20.2 & 23.0 & 21.6 & 11.4 \\
Widowed & & &
\end{tabular}

Figure I below shows that households headed by males were richer than those headed by females. For example, $20.1 \%$ and $21.6 \%$ of the male headed OVC household were in the richer and richest wealth quintiles respectively compared with $19.5 \%$ and
$17.9 \%$ from the female OVC headed households. More female headed OVC households (21.9\%) were found in the middle wealth quintile than the male headed OVC households (I8.0\%).

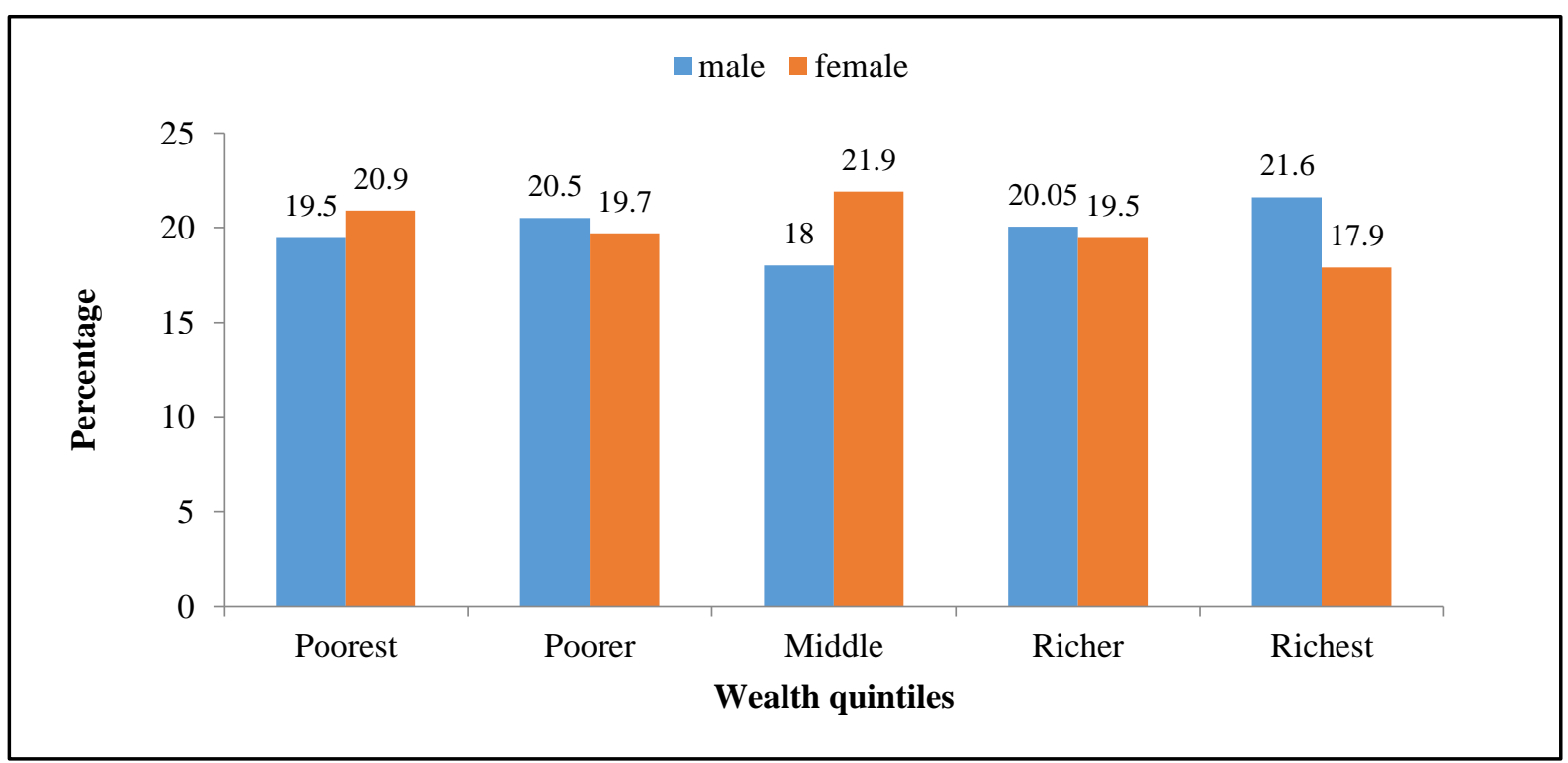

Figure I: Wealth Quintiles of OVC households by Gender of the household head

Wealth Index by OVC key service areas. (Male)

The OVC service areas were also assessed with respect to the wealth status among the males. The results showed that the wellness of the child, child access to health care, safety from abuse, ever attended school, currently in school, attended organized childhood education, and adequacy of food at all times were found to be significantly associated with wealth status $(p<0.05)$.

Majority of the male OVC were reported to be well across all the wealth quintiles. However, there was a slight variation in the proportion as $81.3 \%$ of the OVC from rich households were well compared to $64.7 \%$ of the poorest. Approximately half of the male OVC had access to health care but health care access among the male OVC from the poor households was $35.5 \%$. While $79.5 \%$ of the male OVC were safe from being abused, $78 \%$ ever attended school and $66.0 \%$ were currently in school. None of the male OVC in the richest households worked for money as against $4.9 \%$ of their counterparts from the poorest households. The 
percentage of male OVC attending organized childhood education increased with increasing level of wealth index, but in total, $28.7 \%$ of them attended organized childhood education. About 22\%, $43.0 \%$ and $10.9 \%$ of the male OVC had access to health care professionals, adequate food at all times and vitamin A intake respectively. About $4.4 \%$ and $19.6 \%$ of the male OVC from the richest and poorest households had slept whole day/night without food in the last 4 weeks preceding the survey.

(Table

Table 2A: OVC key service areas by wealth index (male)

\begin{tabular}{|c|c|c|c|c|c|c|c|}
\hline \multirow[t]{2}{*}{ Service Areas } & \multicolumn{5}{|c|}{ Wealth index (\%) } & \multirow[b]{2}{*}{ Total } & \multirow[b]{2}{*}{ Chi } \\
\hline & Poorest & Poor & Middle & Rich & Richest & & \\
\hline Child is healthy & 64.7 & 79.4 & 72.3 & 81.3 & 62.8 & 72.1 & |4.9* \\
\hline Child has access to $\mathrm{HC}$ & 50.1 & 35.5 & 47.9 & 58.9 & 54.0 & 49.3 & $13.15 *$ \\
\hline Possess birth cert & 67.6 & 64.5 & 62.8 & 71.0 & 80.5 & 69.6 & 10.06* \\
\hline Access to legal protection & 24.5 & 15.9 & 13.8 & 16.8 & 19.5 & 18.2 & 4.58 \\
\hline Safe from abuse & 76.5 & 72.0 & 78.7 & 81.3 & 88.5 & 79.5 & $10.18 *$ \\
\hline Progress at home & 64.7 & 69.2 & 67.0 & 76.6 & 63.7 & 68.3 & 5.24 \\
\hline Progress in school & 60.8 & 61.7 & 59.6 & 72.9 & 57.5 & 62.5 & 6.63 \\
\hline Ever attended school & 70.6 & 72.9 & 76.6 & 85.0 & 84.1 & 78.0 & $10.52 *$ \\
\hline Currently in school & 56.9 & 58.90 & 67.00 & 76.60 & 69.90 & 66.00 & $12.42 *$ \\
\hline Worked for money & 4.9 & 3.7 & 2.1 & 0.9 & 0.00 & 2.3 & $\mathrm{nv}$ \\
\hline Attended organized childhood education & 16.7 & 27.10 & 30.90 & 31.80 & 36.30 & 28.70 & II.24* \\
\hline Adequacy of food at all times & 41.2 & 31.8 & 40.40 & 48.60 & 53.1 & 43.20 & $11.94 *$ \\
\hline Food inadequacy (eat smaller meals) & 61.8 & 70.10 & 67.00 & 56.10 & 50.40 & 60.80 & $11.53 *$ \\
\hline Skipped meal in past 4 wks & 56.9 & 57.90 & 52.10 & 42.10 & 44.20 & 50.50 & 8.94 \\
\hline Went to bed hungry & 44.1 & 36.40 & 39.40 & 25.20 & 25.70 & 33.80 & $13.33^{*}$ \\
\hline Whole day/night without food & 19.6 & 10.30 & 11.70 & 13.10 & 4.40 & 11.70 & $12.40 *$ \\
\hline Good growth & 57.8 & 60.70 & 62.80 & 66.40 & 72.60 & 64.20 & 6.09 \\
\hline Access to counselor & 1.0 & 2.80 & 0.00 & 0.90 & 3.50 & 1.70 & $\mathrm{nv}$ \\
\hline Access to health professional & 13.7 & 15.90 & 23.40 & 24.30 & 30.10 & 21.60 & II.24* \\
\hline Access to free school supplies & 5.90 & 4.70 & 6.40 & 0.00 & 4.40 & 4.20 & $\mathrm{nv}$ \\
\hline Access to vitamin $A$ & 12.7 & 5.60 & 7.40 & 11.20 & 16.80 & 10.90 & $8.68 *$ \\
\hline Happy and content & 78.4 & 77.60 & 79.80 & 78.50 & 83.20 & 79.50 & 1.33 \\
\hline Good disposition & 90.2 & 87.90 & 80.90 & 95.30 & 93.80 & 89.90 & $|4.3| *$ \\
\hline Adequate shelter & 49.0 & 37.40 & 39.40 & 58.90 & 58.40 & 48.90 & $17.45^{*}$ \\
\hline Availability of adult who provides care & 66.70 & 72.00 & 76.60 & 86.90 & 92.90 & 79.30 & $30.45 *$ \\
\hline
\end{tabular}

*Significant 5.0\%; nv:chi square test not valid

Wealth Index by OVC key service areas. (Female) Child access to healthcare services increased with increase in wealth index among the female OVC, even though not significant. The proportion of female OVC currently in school was significantly higher in the richest households (83.5\%) compared to other wealth index categories. Similarly, the proportion of female OVC who missed school was highest in the poorest wealth index category (32.1\%). About 36\% of female OVC from the richest households attended organized childhood education compared to $20.8 \%$ of the poorest. Food adequacy at all times was highest in the richest households (53.8\%) compared to the poorest (38.7\%). Similarly the proportion of female OVC who went hungry whole day and night was significantly lower in the richest households (2.2\%) compared to the poorest households (I7.0\%). Furthermore, reported child happiness, and disposition were significantly higher among richest households (86.8\%. and $95.6 \%$ respectively) (Table, 2B).

Table 2B: OVC key service areas by wealth index (female)

\begin{tabular}{l|ccccc|cc}
\hline \multirow{2}{*}{ Service Areas } & \multicolumn{5}{|c|}{ Wealth index (\%) } & \multirow{2}{*}{ Total } \\
\cline { 2 - 6 } & Poorest & Poor & Middle & Rich & Richest \\
\hline Child is healthy & 64.2 & 73.0 & 73.9 & 70.7 & 71.4 & 70.60 & 3.01 \\
Child has access to HC & 46.2 & 42.0 & 47.9 & 46.8 & 54.0 & 47.30 & 3.32 \\
Possess birth cert & 68.9 & 67.0 & 67.6 & 68.7 & 79.1 & 70.00 & 4.49 \\
Access to legal protection & 23.6 & 19.0 & 15.3 & 19.2 & 13.2 & 18.1 & 4.34 \\
Safe from abuse & 70.8 & 81.0 & 84.7 & 83.8 & 87.9 & 81.5 & $11.70 *$ \\
Progress at home & 69.8 & 62.0 & 74.8 & 70.7 & 70.3 & 69.6 & 4.22 \\
\hline
\end{tabular}




\begin{tabular}{l|ccccc|cc}
\hline Progress in school & 65.1 & 55.0 & 67.6 & 64.6 & 61.5 & 62.9 & 4.13 \\
Ever attended school & 79.2 & 78.0 & 74.8 & 78.8 & 83.5 & 78.7 & 2.33 \\
Currently in school & 66.0 & 59.0 & 63.1 & 67.7 & 70.3 & 65.1 & 3.27 \\
Worked for money & 2.8 & 3.0 & 1.8 & 1.0 & 1.10 & 2.0 & $\mathrm{nv}$ \\
Attended organized childhood education & 20.8 & 25.0 & 26.1 & 23.2 & 36.30 & 26.0 & 6.94 \\
Adequacy of food at all times & 38.7 & 47.0 & 44.1 & 52.5 & 53.8 & 46.9 & 6.24 \\
Food inadequacy (eat smaller meals) & 67.9 & 65.0 & 76.6 & 69.7 & 41.8 & 64.9 & $29.4 *$ \\
Skipped meal in past 4wks & 59.4 & 54.0 & 60.4 & 57.6 & 33.0 & 53.5 & $19.69 *$ \\
Went to bed hungry & 46.2 & 34.0 & 36.0 & 48.5 & 20.9 & 37.5 & $19.89 *$ \\
Whole day/night without food & 17.0 & 9.0 & 15.3 & 18.2 & 2.2 & 12.6 & $15.49 *$ \\
Good growth & 55.7 & 60.0 & 66.7 & 64.6 & 75.8 & 64.3 & $9.79 *$ \\
Access to counselor & 2.8 & 2.0 & 0.90 & 0.0 & 9.9 & 3.0 & $\mathrm{nv}$ \\
Access to health professional & 16.0 & 14.0 & 21.6 & 14.1 & 31.9 & 19.3 & $13.82 *$ \\
Access to free school supplies & 9.4 & 3.0 & 6.3 & 3.0 & 2.2 & 2.6 & $\mathrm{nv}$ \\
Access to vitamin A & 11.3 & 7.0 & 17.1 & 11.1 & 19.8 & 13.2 & $8.98^{*}$ \\
Happy and content & 76.4 & 76.0 & 87.4 & 75.8 & 86.8 & 80.5 & 9.49 \\
Good disposition & 84.0 & 92.0 & 93.7 & 94.9 & 95.6 & 91.9 & $12.38^{*}$ \\
Adequate shelter & 41.5 & 38.0 & 39.6 & 53.5 & 57.1 & 45.6 & $12.04 *$ \\
Availability of adult who provides care & 60.4 & 63.0 & 80.2 & 80.8 & 90.1 & 74.6 & $33.77^{*}$ \\
\hline
\end{tabular}

**Significant at 5.0\%; nv: chi square test not valid

\section{Logistic Regression results: Males}

Male OVC from poorest households were less likely to have access to healthcare compared to those from the richest households $(\mathrm{OR}=0.55,95 \% \mathrm{Cl}=0.316$ 0.959). The odds of been currently in school was lower in the lower wealth quintiles compared to the higher quintiles. Male OVC in poorest households were less likely to have adequate food at all times compared to those in the richest households. (OR = $0.665,95 \% \mathrm{Cl}=0.378-\mathrm{I} .173)$. Similarly, male OVC in poorest households were also less likely to have stable shelter compared to their counterparts from the richest households. $(\mathrm{OR}=62 \mathrm{I}, 95 \% \mathrm{Cl}=0.358$ 1.078). Table $3 A$ shows the results of the logistic regression among male OVC.

Table 3A: Odds ratios (OR) and $95 \% \mathrm{Cl}$ for the OVC service areas in different wealth index categories in male respondents

\begin{tabular}{|c|c|c|c|c|c|}
\hline \multirow[t]{2}{*}{ Service area } & Poorest & Poorer & Middle & Richer & \multirow[t]{2}{*}{ Richest $†$} \\
\hline & $\begin{array}{l}\text { Odds Ratio } \\
(95 \% \text { C.I) }\end{array}$ & $\begin{array}{l}\text { Odds Ratio } \\
(95 \% \text { C.I) }\end{array}$ & $\begin{array}{l}\text { Odds Ratio } \\
\text { (95\% C.I) }\end{array}$ & $\begin{array}{l}\text { Odds Ratio } \\
\text { (95\% C.I) }\end{array}$ & \\
\hline Access to healthcare & $\begin{array}{c}0.551 \\
(0.316-0.959)\end{array}$ & $\begin{array}{c}0.918 \\
(0.524-1.609)\end{array}$ & $\begin{array}{c}1.423 \\
(0.829-2.474)\end{array}$ & $\begin{array}{c}1.173 \\
(0.686-2.005)\end{array}$ & $\mathrm{I}$ \\
\hline Ever attended school & $\begin{array}{c}1.121 \\
(0.613-2.047)\end{array}$ & $\begin{array}{c}1.364 \\
(0.7 \mid 9-2.586)\end{array}$ & $\begin{array}{c}2.370 \\
(1.199-4.682)\end{array}$ & $\begin{array}{c}2.199 \\
(1.137-4.254)\end{array}$ & 1 \\
\hline Currently in school & $\begin{array}{c}1.086 \\
(0.627-1.882)\end{array}$ & $\begin{array}{c}1.542 \\
(0.862-2.758)\end{array}$ & $\begin{array}{c}2.488 \\
(1.372-4.5 \mathrm{II})\end{array}$ & $\begin{array}{c}1.763 \\
(1.005-3.090)\end{array}$ & $\mathrm{I}$ \\
\hline Adequate food & $\begin{array}{c}0.665 \\
(0.378-1.173)\end{array}$ & $\begin{array}{c}0.969 \\
(0.548-1.715)\end{array}$ & $\begin{array}{c}.35 \mathrm{I} \\
(0.782-2.334)\end{array}$ & $\begin{array}{c}1.617 \\
(0.942-2.776)\end{array}$ & I \\
\hline Eat smaller meals & $\begin{array}{c}1.451 \\
(0.816-2.579) \\
\end{array}$ & $\begin{array}{c}1.258 \\
(0.700-2.262) \\
\end{array}$ & $\begin{array}{c}0.790 \\
(0.4 \mid 5-1.373) \\
\end{array}$ & $\begin{array}{c}0.630 \\
(0.366-1.085) \\
\end{array}$ & 1 \\
\hline Stable shelter & $\begin{array}{c}0.621 \\
(0.358-1.078)\end{array}$ & $\begin{array}{c}0.675 \\
(0.383-1.191) \\
\end{array}$ & $\begin{array}{c}1.489 \\
(0.862-2.573)\end{array}$ & $\begin{array}{c}1.460 \\
(0.852-2.504)\end{array}$ & $\mathrm{I}$ \\
\hline $\begin{array}{l}\text { Good disposition with } \\
\text { peers/adults }\end{array}$ & $\begin{array}{c}0.786 \\
(0.328-1.882) \\
\end{array}$ & $\begin{array}{c}0.459 \\
(0.200-1.053) \\
\end{array}$ & $\begin{array}{c}2.217 \\
(0.731-6.728) \\
\end{array}$ & $\begin{array}{c}1.646 \\
(0.602-4.499) \\
\end{array}$ & 1 \\
\hline $\begin{array}{l}\text { Availability of adult who } \\
\text { gives care }\end{array}$ & $\begin{array}{c}1.283 \\
(0.7|2-2.3| 4)\end{array}$ & $\begin{array}{c}1.636 \\
(0.87 \mid-3.074) \\
\end{array}$ & $\begin{array}{c}3.321 \\
(1.655-6.665)\end{array}$ & $\begin{array}{c}6.562 \\
(2.866-15.03) \\
\end{array}$ & 1 \\
\hline
\end{tabular}

tRef category

\section{Logistic Regression results: females}

The odds of not experiencing abuse and exploitation increased with increasing wealth quintiles among female respondents and was highest in the richer households. $(\mathrm{OR}=3.0,95 \% \mathrm{Cl}=1.4 \mathrm{I} \mid-6.406)$. The odds of reported good child growth also increased with increase in wealth quintile and was highest in the richer households. $(\mathrm{OR}=2.498,95 \% \mathrm{Cl}=1.352-$ 4.617). The odds of going hungry day and night was significantly lowest in the richer households 
$(\mathrm{OR}=0.1 \mathrm{I} 0,95 \% \mathrm{Cl}=0.025-0.488)$. Likewise the odds of eating smaller meals, skipping meals and going to bed hungry was lowest in the richer households. Female respondents from poorest households were less likely to have adequate shelter compared to those from the richest households $(\mathrm{OR}=0.864,95 \% \mathrm{Cl}=0.494-\mathrm{I} .5 \mathrm{I})$. The OVC from richer households also had higher odds of having caregivers to take care of them. Table 3B shows the results of the logistic regression analysis for females.

Table 3B: Odds ratios (OR) and $95 \% \mathrm{Cl}$ for the OVC service areas in different wealth index categories in female respondents

\begin{tabular}{|c|c|c|c|c|c|}
\hline Service area & $\begin{array}{l}\text { Poorest } \\
\text { Odds Ratio } \\
\text { (95\% C.I) }\end{array}$ & $\begin{array}{c}\text { Poorer } \\
\text { Odds Ratio } \\
(95 \% \text { C.I) }\end{array}$ & $\begin{array}{l}\text { Middle } \\
\text { Odds Ratio } \\
\text { (95\% C.I) }\end{array}$ & $\begin{array}{c}\text { Richer } \\
\text { Odds Ratio } \\
\text { (95\% C.I) }\end{array}$ & Richest $†$ \\
\hline $\begin{array}{l}\text { Child does not seem to } \\
\text { be abused }\end{array}$ & $\begin{array}{c}1.76 \\
(0.918-3.38 \mid)\end{array}$ & $\begin{array}{c}2.285 \\
(1.176-4.443)\end{array}$ & $\begin{array}{c}2.244 \\
(1.087-4.23)\end{array}$ & $\begin{array}{c}3.006 \\
(1.411-6.406)\end{array}$ & $\bar{I}$ \\
\hline $\begin{array}{l}\text { Child went day andnight } \\
\text { hungry }\end{array}$ & $\begin{array}{c}0.484 \\
(0.206-I .134)\end{array}$ & $\begin{array}{c}0.884 \\
(0.429-1.823)\end{array}$ & $\begin{array}{c}1.086 \\
(0.529-2.231)\end{array}$ & $\begin{array}{c}0.110 \\
(0.025-0.488)\end{array}$ & I \\
\hline $\begin{array}{l}\text { Child had to eat smaller } \\
\text { meal }\end{array}$ & $\begin{array}{c}0.877 \\
(0.492-1.565) \\
\end{array}$ & $\begin{array}{c}1.544 \\
(0.848-2.811)\end{array}$ & $\begin{array}{c}1.086 \\
(0.601-1.963) \\
\end{array}$ & $\begin{array}{c}0.339 \\
(0.189-0.607) \\
\end{array}$ & 1 \\
\hline Child skipped a meal & $\begin{array}{c}0.801 \\
(0.461-1.392)\end{array}$ & $\begin{array}{c}1.039 \\
(0.604-1.789)\end{array}$ & $\begin{array}{c}0.926 \\
(0.531-1.615)\end{array}$ & $\begin{array}{c}0.336 \\
(0.187-0.602)\end{array}$ & $\mathrm{I}$ \\
\hline Child went to bed hungry & $\begin{array}{c}0.599 \\
(0.341-1.052)\end{array}$ & $\begin{array}{c}0.655 \\
(0.380-1.129)\end{array}$ & $\begin{array}{c}1.095 \\
(0.632-1.895)\end{array}$ & $\begin{array}{c}0.307 \\
(0.163-0.578)\end{array}$ & I \\
\hline Child is well grown & $\begin{array}{c}1.195 \\
(0.687-2.079) \\
\end{array}$ & $\begin{array}{c}1.593 \\
(0.919-2.762) \\
\end{array}$ & $\begin{array}{c}1.457 \\
(0.83-2.557) \\
\end{array}$ & $\begin{array}{c}2.498 \\
(1.352-4.617)\end{array}$ & $\mathrm{I}$ \\
\hline $\begin{array}{l}\text { Child received healthcare } \\
\text { from professional }\end{array}$ & $\begin{array}{c}0.852 \\
(0.396-1.835) \\
\end{array}$ & $\begin{array}{c}1.444 \\
(0.726-2.874) \\
\end{array}$ & $\begin{array}{c}0.862 \\
(0.400-1.857) \\
\end{array}$ & $\begin{array}{c}2.449 \\
(1.240-4.838)\end{array}$ & $\mathrm{I}$ \\
\hline Received vitamin A & $\begin{array}{c}0.590 \\
(0.222-1.564)\end{array}$ & $\begin{array}{c}1.618 \\
(0.743-3.521)\end{array}$ & $\begin{array}{c}0.979 \\
(0.411-2.333)\end{array}$ & $\begin{array}{c}1.932 \\
(0.875-4.264)\end{array}$ & 1 \\
\hline $\begin{array}{l}\text { Good disposition with } \\
\text { peers/adults }\end{array}$ & $\begin{array}{c}2.197 \\
(0.903-5.346)\end{array}$ & $\begin{array}{c}2.838 \\
(1.126-7.154)\end{array}$ & $\begin{array}{c}3.591 \\
(1.271-10.14)\end{array}$ & $\begin{array}{c}4.154 \\
(1.344-12.842)\end{array}$ & I \\
\hline Stable shelter & $\begin{array}{c}0.864 \\
(0.494-1.510)\end{array}$ & $\begin{array}{c}0.925 \\
(0.538-1.591)\end{array}$ & $\begin{array}{c}1.624 \\
(0.934-2.821)\end{array}$ & $\begin{array}{c}1.879 \\
(1.066-3.313)\end{array}$ & I \\
\hline $\begin{array}{l}\text { Availability of adult who } \\
\text { gives care }\end{array}$ & $\begin{array}{c}1.117 \\
(0.637-1.961)\end{array}$ & $\begin{array}{c}2.655 \\
(1.446-4.875)\end{array}$ & $\begin{array}{c}2.763 \\
(1.466-5.208)\end{array}$ & $\begin{array}{c}5.979 \\
(2.7 \mid 2-13.183)\end{array}$ & 1 \\
\hline
\end{tabular}

tRef category

\section{Discussion}

Nigeria as the most populous country in Africa has a high burden of OVC. The health services, nutritious food, education and other social infrastructures are often not within the reach of the poor. The situation is compounded by poverty which ravages the population. Thus these conditions put the life of the poor in Nigeria at risk and the socio-economic advancement of the children particularly the OVC living in poor households may be compromised. In this study, OVC residing in vulnerable households were identified and disaggregated into five groups based on their wealth status. Past studies in Nigeria have revealed differential in children's access to service area by gender and most families have preference for male children (Adebowale et al, 2014). We therefore examined the relationship between the wealth status of households where OVC lives and their access to OVC service areas by gender.

In this study, we found slight differences in the composition of wealth index categories of OVC households. However, our findings were similar to http://aps.journals.ac.za that of the national figures for all households (OVC and non-OVC) (NDHS, 20I3) with about $20 \%$ of the population in each wealth quintile. Similar results were also reported in Kenya where the wealth index of OVC was slightly less than $30 \%$ in each quintile (Mishra and Assche 2008). However, in Cameroon, Cote devoire, Lesotho, Malawi, Tanzania, Uganda and Zimbabwe, gross disparities exists in the wealth quintiles with high proportions in the wealth categories than ours. (Mishra et al, 2008). Possible reasons could be that these countries have higher HIV prevalence and the response to the epidemic is greater than in Nigeria. Our study focused on OVC households (which was not HIV specific) and their distribution by wealth may likely differ from that of a population where the OVC where strictly by reasons of HIV. However, poverty assessment of OVC in Rwanda revealed that $12 \%$ OVC were in abject poverty, $47.3 \%$ were rated as very poor and only $0.7 \%$ were rated as the "money rich". The instrument used in the poverty assessment in Rwanda which classified poverty into six classes (abject poverty, very poor, poor, resourceful poor, food rich 
and the money rich) instead of five in our study may also explain these differentials. (EDPRS and MINECOFIN, 2007).

The present study also observed that more females OVC were living in poorer households than the males $(20.9 \%$ vs $19.5 \%)$. Similar finding of poorer females was also reported elsewhere. (Theilman et al 20/2).Contrarily, in Swaziland, a child poverty study showed that boys were poorer than girls (7I\% vs 69\%). (UNICEF, 20I3). In Nigeria, preference is given to the male child and some cultural norms and traditions always favour the male children even in the poor households. This may account for the slight increase in the wealth status of the male OVC compared to the females.

Wealth index was found to be associated with some certain OVC service areas including food insecurity, education, adequate shelter, child growth, psychosocial items as well as availability of adult caregiver who nurtures the child. Disparities were found in the wealth index of males/females with respect to the service areas such as food security. Several factors have been found to affect or determine food insecurity one of which is gender, and household characteristics, such as income, number of children, and parental characteristics. In this study, female respondents reported higher risk of food insecurity compared to the males. This outcome is in contrast to a study in Kenya where female OVC had better outcomes in food security scores compared to the males. (Kimani-Murage et al, 2010)

Even though majority of OVC were healthy, access to health care services was poor and respondents from rich households had better access to healthcare compared to those in poor or poorer households. The odds of health care access also increased with increasing wealth index. Some studies (Achwoka, 20II) in Kenya and Tanzania had reported poorer access to healthcare among female OVC in poor households. Possession of birth certificate was also higher among OVC from rich households compared to those in poorer households. Again gender disparity was observed in the proportion of females possessing birth certificate lower than that of their male counterparts in the rich wealth quintiles; however the converse situation was observed in the lower wealth index categories. Some studies have identified gender as a risk factor for poor health outcomes among the OVC. (ODonell et al, Chen et al, 198I, Rousham, 1996). In addition, it has been documented that young females are more likely to contract HIV and other STls than the males and they also lack access to healthcare. (Birdthistle, et al 2008, Dunbar et al 2010, Gregson 2005, Krishnan 2008).
The environment that a child lives has implication for their health and survival. Poor shelter during childhood has been shown to be associated with childhood morbidity and mortality. In this case OVC living in a poor setting will be more at risk of childhood diseases and infections. In the current study, we found that adequate shelter was higher in the rich OVC households compared to those in the lower wealth index categories. This is not surprising as the proportion with good shelter is expected to be higher among people with better socio economic status.

Access to legal protection was low for both males and females. However, the OVC were not at a disadvantage in terms of safety from abuse and exploitation which was high in all wealth quintiles. In the Africa context, taking legal means against a benefactor is seen as a taboo and child access to legal support is a difficult task particularly among OVC living in vulnerable households. Where such facilities are in place, the level of awareness and need to report the perpetrators of child abusers is uncommon in Nigeria. To our knowledge we didn't find any studies reporting access to legal protection among OVC. However, in Cote d'lvoire and Ghana, some OVC had access to succession plans. A succession plan helps ensure that children will receive appropriate care and support in the event of a death of a parent or primary caregiver. (Mishra and Assche 2008).

Regarding education, majority of males had ever attended school but only slightly above half were currently in school. The same pattern was recorded for the females but those that were currently in school among the females were slightly lower than the males who were currently in school. Again our findings point to the traditional notion of not educating the female child as much as the males. Although, paradigm shift in female education has been observed in Nigeria in the past few decades with more enrolment of female children than it used to be in the past but higher school enrolment was still found among males than females. Male OVC in middle and richer households had significantly higher odds of being currently in school, while the poor had lower odds of not being in school compared to the richest. Findings from other African studies are similar; majority of orphans in Swaziland were in school although progression from primary to secondary was low. (UNICEF 2013). In Rwanda, the situation is similar with about $85 \%$ of $6-17 y r$ olds in school. (UNICEF, 2008). Inspite of the current schooling, both male and female OVC made more progress at home than at school. Very few had attended any childhood education program, and this was slightly higher among the males. 
More males and lesser females OVC had worked for money; in particular none of the males from richest households had worked for money. In our study $4.9 \%$ of the poorest males versus $2.8 \%$ of poorest females had worked for money. The figure is found to be lower than a previous study where $15.4 \%$ of HIV-OVC had worked for their families (MyoMyoMon et al 20/3). An explanation for this is the fact that our study was not HIV specific in other words the OVC in this study were not OVC due to HIV alone. The households where they live were identified using the child vulnerability index.

Richer OVC households reported good child growth, access to vitamin A and access to healthcare professionals compared to poor/poorer households. This finding was consistent for both males and females. The direction is expected as richer OVC households are likely to have more educated and better household heads than the poorer households. Richer households are expected to have a better socio-economic status. The psychosocial aspects of life are important to child development, health and future aspirations. Psychosocial items (happiness, contentment, good disposition towards adults and peers, and availability of adult care givers who nurtures) were found to be higher among both male and female OVC living in the rich quintiles compared to the lower quintiles.

\section{Conclusion:}

There were considerable socio economic inequalities in the access of OVC to the service areas. Since few resources are available to care for the OVC, it becomes important to identify the core service areas that need more support/attention. Steps that will ensure food security, foster gender equality are important in order to improve the socio economic status of orphans and vulnerable children.

\section{Acknowledgements}

We thank the community volunteers and $\mathrm{CBO}$ s who provided access to the caregivers of the OVC. We also thank Ms Linda Ugalahi who was part of the statistical analysis. This project received support from the Local Partners for Orphans and Vulnerable Children (LOPIN) /USAID project (620-00004).

\section{References}

Achwoka, D. E. (20II). An Assessment of health outcomes among orphans in the positive outcomes for orphans study in rural settings of Kenya and Tanzania. Thesis submitted for masters of Science Duke Global health institute in the Graduate school of Duke University.

Adebowale, S.A, Yusuf, O.B, Palmuleni, E.A (20I4). Child's Gender Preference: What isthe Regional
Situation among women in Nigeria? Gender \&Behaviour, 12(3): 5868-5884

Allen, S.S., Bade, T., Hatsukami, D., Craving C.B. (2008). Withdrawal, and smoking urges on days immediately prior to smoking relapse. Nicotine Tob Res. 10: 35-69

Birdthistle, I.J., Floyd, S., Machingura, A., Mudziwapasi, N., Gregson, S., Glynn, J.R. (2008). From affected to infected? Orphanhood and HIV risk among female adolescents in urban Zimbabwe. AIDS 22: 759-766.

Braithwaite, J., Djima, I.Y. and Pickmans, R. (20I3). Child and orphan poverty in Swaziland

Celik, Y., Hotchkiss, D.R. (2000). The socioeconomic determinants of maternal health care utilization in Turkey. SocSci Med. 5: I 797-I806.

Chen, L.C., Huq, E., D'souza, S. (1981). Sex bias in the family allocation of food and health care in rural Bangladesh. Popul Dev Rev. 7: 55-70.

Christian Aid (2007). Orphans and Vulnerable Children Baseline Survey 2007.

Dalstra, J.A.A, Oyen, H. V., Kunst, A.E., Rasmussen, N.K., Borrell, C., Breeze, E., Regidor, E., Cambois, E., Spadea, T. (2005). Socioeconomic differences in the prevalence of common chronic diseases: an overview of eight European countries. International Journal of Epidemiology. 34: 316326.

Dejana, Vukovic, Vesna, Bjegovic (2008). Prevalence of Chronic Diseases According to Socioeconomic Status Measured by Wealth Index: Health Survey in Serbia. Croat Med J. 2008;49:832- 4 I

Dunbar, M.S., Maternowska, M.C., Kang, M.S., Laver, S.M., Mudekunye-Mahaka, I., Padian, N.S. (20I0). Findings from SHAZ: A feasibility study of a microcredit and life-skills HIV prevention intervention to reduce risk among adolescent female orphans in Zimbabwe. I Previnterv Community 38: |47-|6|.[

Economic Development and Poverty Reduction Strategy (EDPRS) 2007

Egharevba M. 2017. Demographic dynamics, governance and the attainment of democratic development: The case of Nigeria. African Population Studies. Vol 3I (2):3769-3787

Federal Ministry of Womens' Affairs and Social Development (FMW\&SD). 2007. National standards for improving the quality of life of vulnerable children in Nigeria.

Federal Ministry of Womens' Affairs and Social Development (FMW\&SD) 20I4. National Standards for Improving the Quality of care of Orphans and Vulnerable children in Nigeria. www.womenaffairs.gov.ng

Filmer, D. and Prichett, L. (1999). "The Effect of Household Wealth on Educational Attainment: 
Evidence from 35 Countries." Population and Development Review 25(I):85-I 20.

Gregson, S., Nyamukapa, C.A., Garnett, G.P., Wambe, M., Lewis, J.J., Mason, P.R., .Chandiwana, S.K, Anderson, R.M. (2005). HIV infection and reproductive health in teenage women orphaned and made vulnerable by AIDS in Zimbabwe. AIDS Care 17: 785-794.

Kimani-Murage, E.W., Holding, P.A., Fotso, J., Ezeh, A.C., Madise, N.J., Kahurani, E.N., and Zulu, E.M. (2010). Food Security and Nutritional Outcomes among Urban Poor Orphans in Nairobi, Kenya Journal of Urban Health: Bulletin of the New York Academy of Medicine 88(2)

Krishnan, S., Dunbar, M.S., Minnis, A.M., Medlin, C.A., Gerdts, C.E., Padian, N.S. (2008). Poverty, gender inequities, and women's risk of human immunodeficiency virus/AIDS. Ann NY AcadSci II36: I0I-110.

Ministry of Finance and Economic Planning ( MINECOFIN ) (20II). Government of Rwanda Simplified Public Financial guidelines for Chief Budget Managers

Mishra, V. and Simona Bignami,V. (2008). Orphans and Vulnerable Children in High HIV Prevalence Countries in Sub-Saharan Africa. DHS Analytical Studies No. 15. Calverton, Maryland, USA: Macro International Inc.

Mohanty, S.K. (2008). Alternative wealth indices and health estimates in India 580 Genus. 2008; LXV: I I 3-37.

National Population Commission. (20I3). Federal Republic of Nigeria: final report on Nigeria Demographic and Health Survey 2013. Calverton, MD, USA: ORC Macro.

Nigeria Research Situation Analysis on Orphans and other vulnerable children (2009). Country Brief. Boston University center for Global Health and Development.
O'Donnell, K., Nyangara, K., Murphy, R.A., Nyberg, B. (20I I). Child Status Index: A Tool for Assessing the Well-Being of Oprhans and Vulnerable Children - Manual. Available: http://www.cpc.unc.edu/measure/tools/childhealth/child-statusindex.

Ortiz, A.V. (2007). Determinants of demand for antenatal care in Colombia. Health Policy (New York )86: 363-72.

Pollack, C.E., Chideya, S., Cubbin, C., Williams, B., Dekker, M., Braveman, P. (2007). Should health studies measure wealth? A systematic review. Am J Prev Med. 33: 250-64

Rousham, E.K. (1996). Socio-economic influences on gender inequalities in child health in rural Bangladesh. Eur J ClinNutr 50: 560-564.

Rutstein,, S.O., Johnson, K. (2004).The DHS Wealth Index: DHS Comparative Reports. ORC Macro, USA: Calverton; 2-77

Rutstein, S.O., (2008). The DHS Wealth Index: Approaches for rural and urban areas. ORC Macro, USA: Calverton; No. 60.

Thielman, N., Ostermann, J., Whetten, K., Whetten, R., O'Donnell, K., et al. (20I2) Correlates of Poor Health among Orphans and Abandoned Children in Less Wealthy Countries: The Importance of Caregiver Health. PLoS ONE 7(6): e38109. doi: $10.1371 /$ journal.pone.0038109

UN Secretary-General, (20I I). Uniting for universal access. Report of the Secretary-General. 28 March $201 \mathrm{I}$.

UNICEF (2008). A Situation Analysis of Orphans and Other Vulnerable Children in Rwanda.

UNICEF (20I3). Towards an AIDS-Free Generation - Children and AIDS: Sixth Stocktaking Report, 2013' - http://www.avert.org/children-orphanedhiv-and-aids.htm\#sthash.oNVBBdex.dpuf 